\title{
Interaction of vitamins $B 3$ and $C$ and their radicals with $(5,0)$ single-walled boron nitride nanotube for use as biosensor or in drug delivery
}

\author{
DAVOOD FARMANZADEH* ${ }^{*}$ and SAMEREH GHAZANFARY \\ Department of Physical Chemistry, Faculty of Chemistry, University of Mazandaran, \\ Babolsar 47416-95447, I R, Iran \\ e-mail: d.farmanzad@umz.ac.ir
}

MS received 1 April 2013; revised 22 July 2013; accepted 12 August 2013

\begin{abstract}
Electronic properties of the covalent and noncovalent adsorption of single-walled boron nitride nanotube with vitamins B3 and $\mathrm{C}$ and their radicals are investigated through the density functional theory. Results show that noncovalent and covalent adsorption of vitamin B3 on BNNT could make these systems of interest for drug delivery purposes due to the possibility of easily detaching the pristine molecule from the BNNT surface. Noncovalent and covalent adsorption of vitamin C on BNNT result in modification of the electronic properties of BNNT, these results are extremely relevant in identifying the potential application of functionalized BNNT with vitamin $\mathrm{C}$ as nano-sensor. The present results are expected to provide useful guidance for the relevant experimental study.
\end{abstract}

Keywords. Vitamin C; vitamin B3; density functional theory; boron nitride nanotube (BNNT).

\section{Introduction}

The recent explosive growth of nanotechnology has caused dramatic advances in pharmacology and is revolutionizing the delivery of biologically active compounds. Development of new and efficient drug delivery systems is of fundamental importance to improve the pharmacological profiles of many classes of therapeutic molecules. Many different types of drug delivery systems are currently available. Within the family of nanomaterials, nanotubes have emerged as a new alternative and efficient tool for transporting therapeutic molecules as nanotubes can easily shuffle cargos within cellular membranes through endocytosis. ${ }^{1-8}$ Moreover, nanotubes could act also as sensors to identify changes in the adsorbed molecules. The need for detectors with high specificity and sensitivity has directed scientists to investigate nanotubes. At many times, chemical sensors developed from nanotubes have their acts based on the electrical properties that they have to change such as their conductance, by replying chemically with other structures. Sensors made from nanotubes have fast response time at room temperature and high sensitivity due to their large surface areas to volume ratios

*For correspondence which are important advantages for sensing applications. In particular, nanotubes can be particularly useful for detecting biological structures. ${ }^{9-14}$

BNNT with its outstanding thermal, ${ }^{15}$ mechanical, ${ }^{16}$ chemical $^{17}$ and electrical ${ }^{18}$ properties has attracted huge attention, since its discovery in 1995. These advantageous properties make BNNT promising material for application in nano-devices, material science, bio-technology and electronic devices in certain hazardous and high temperature environments. BNNTs are also found to be nontoxic to health and environment; therefore, they are suitable for bio-medical applications. ${ }^{19}$ Recent studies showed that BNNTs have attracted attention in the field of nanomedicine, ${ }^{20}$ both as nanovectors for drug delivery purpose, as intracellular nanotransducers ${ }^{21}$ and for the development of biosensors. ${ }^{22-24}$ On the theoretical side, interaction of BNNTs with amino acids, ${ }^{25}$ nucleobases ${ }^{26}$ and thiazole ${ }^{27}$ has been reported previously. These studies suggested that BNNT can be used as a smooth nanoscale channel for transporting biological molecules and nanovector for targeted drug delivery. Consequently, it is important to understand the advantages and disadvantages of functionalizations of BNNTs for increasing their biocompatibility and further their application for drug delivery and as biosensor.

On the other hand, modification of the electronic and physical properties of nanotubes by doping and 
functionalizing is an important subject for designing of the nano-devices. Functionalized nanotubes may exhibit a dramatic change with regard to the isolated nanotubes thus, functionalization is a commonly used method to enhance the electronic properties. ${ }^{28}$ From the theoretical results, it is reported that covalent functionalizations of BNNTs by using, $\mathrm{NH}_{3},{ }^{29,30}$ Fluorine $^{31}$ and $\mathrm{CCl}_{2},{ }^{32}$ can effectively modify their solubility, magnetic properties and electronic structures.

Noncovalent functionalizations of BNNTs have also been extensively explored. Theoretical studies of noncovalent functionalizations of BNNTs using organic molecules, ${ }^{33}$ nucleobases, ${ }^{34}$ polymers, ${ }^{35}$ various metalloporphyrins, ${ }^{36}$ various gas molecules ${ }^{37}$ and $\mathrm{H}_{2}$ molecule ${ }^{38}$ have been reported. These studies on the noncovalent functionalizations of BNNTs provide a guidance to design BNNT-based devices such as sensing devices, molecular electronics and biomedical applications.

To our knowledge, no investigations have been reported on the interaction of vitamins $\mathrm{B} 3$, and $\mathrm{C}$ and their radicals with BNNTs. With an aim of expanding the domain of BNNT for drug delivery and as biosensor, we have studied the covalent and noncovalent functionalizations of $(5,0)$ BNNT with vitamins $\mathrm{B} 3$ and $\mathrm{C}$.

Interest in the theoretical study of vitamins B3 and $\mathrm{C}$ stems from the fact that vitamins are essential nutrients found in foods. The requirements are small but they perform specific and vital functions essential for maintaining health. Vitamin $\mathrm{C}$ is a water-soluble, antioxidant vitamin. It is important in forming collagen, a protein that gives structure to bones, cartilage, muscle and blood vessels. Vitamin $\mathrm{C}$ also aids in the absorption of iron, and helps maintain capillaries, bones and teeth. In the same view, vitamin B3 is part of the B complex of vitamins. All of the B vitamins are watersoluble, which makes it less likely for people to develop any levels of toxicity. Vitamin B3 along with the other $B$ vitamins converts carbohydrates into sugar, which is then used to produce energy for the body. It is also vital for maintaining muscle tone, especially along the digestive tract. It is also required for the health of hair, skin, eyes, mouth, liver and nervous system. Also, the adsorption of biological molecules on nanotubes has attracted such attention during the recent years, since it is of great importance both from the fundamental and the applied point of view. ${ }^{25}$ It is important to be able to predict the interaction between vitamins B3 and $\mathrm{C}$ and BNNTs with changes in electronic structure in order to determine the nature of biological-nanotube interactions, and this knowledge is also significant for understanding their biological activity as well as the potential role they can play in nanostructure construction, BNNT-based drug delivery and biosensor systems. ${ }^{39}$

\section{Computational details}

Full geometry optimizations and all calculations were performed on the $(5,0)$ pristine and covalent and noncovalent functionalized single-walled boron nitride nanotube (SWBNNT) with vitamins B3 and $\mathrm{C}$ at the spin unrestricted B3LYP/6-31G* level of the theory as implemented in Gaussian 03 suites of program. ${ }^{40}$ The B3LYP/6-31G* is a popular approach commonly used for nanotube structures. ${ }^{41-46}$ We considered the $(5,0)$ SWBNNT with a $1 \mathrm{~nm}$ length, $0.42 \mathrm{~nm}$ dimeter which consists of $20 \mathrm{~B}$ and $20 \mathrm{~N}$ atoms. Due to the absence of periodic boundary conditions in molecular calculations, it is necessary to saturate the $\mathrm{B}$ and $\mathrm{N}$ dangling bonds with hydrogen atoms. It is important to note that due to the size effects and limitations in living systems, considering small nanotubes is very important for biologically related applications ${ }^{47}$ Geometry optimizations were carried out until the maximum force and root-mean-square errors on all atoms were less than 0.00045 and 0.00030 Hartree/Bohr, respectively, which are the 'normal' convergence criteria setting in Gaussian 03. Analyses of the electronic properties of the BNNT-vitamin system were based on adsorption energy, the gap of highest occupied molecular orbital (HOMO) and the lowest unoccupied molecular orbital (LUMO), charge transfer (NBO charge) and density of states (DOSs).

\section{Results and discussion}

\subsection{Noncovalent interaction of vitamins B3 and $C$ with $(5,0) B N N T$}

Optimized structures for vitamins B3, C and pristine $(5,0)$ BNNT are shown in figure $1 \mathrm{a}, \mathrm{b}$ and $\mathrm{c}$, respectively. To model the noncovalent interaction between BNNT and vitamins B3 and C, these vitamins are located parallel to the BNNT axis. Vitamins B3 and C atoms are allowed to relax freely in all directions, to determine the stable adsorption structures. Optimized structures of the BNNT-vitamin B3 and BNNT-vitamin $\mathrm{C}$ complexes are shown in figure $1 \mathrm{~d}$ and $\mathrm{f}$, respectively.

From the optimized configurations, we find that adsorption of vitamin B3 on BNNT mainly arises from interaction between $\mathrm{N}$ atom in the tube and $\mathrm{H}$ atom of the hydroxyl group in vitamin B3, while the pyridine ring in vitamins B3 does not contribute towards 


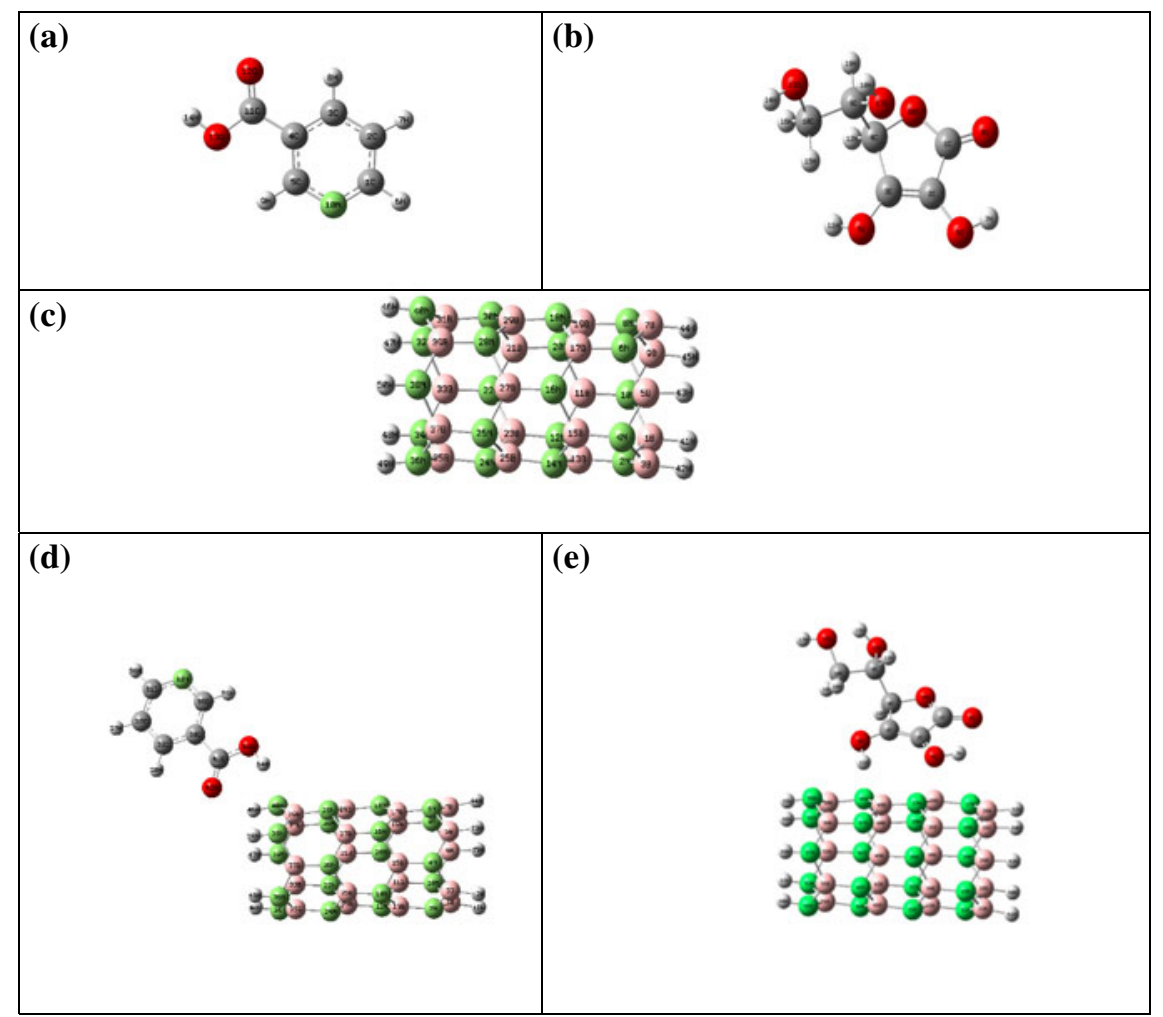

Figure 1. Fully optimized structures of (a) vitamin B3, (b) vitamin C, (c) $(5,0)$ BNNT, (d) BNNT-vitamin B3 complex and (e) BNNT-vitamin C complex.

the adsorption interaction. This indicates that BNNT prefers to adsorb vitamin B3 via the polar interaction rather than the $\pi-\pi$ stack between the tube and the vita$\min$. As indicated by geometry of panel 'e' in figure 1, the furan ring in vitamin $\mathrm{C}$ slightly slopes to the tube surface, implying that there is $\pi-\pi$ attraction interaction between the tube and vitamin $\mathrm{C}$. Furthermore, the $\mathrm{H}$ atom in vitamin $\mathrm{C}$ also has polar interaction with $\mathrm{N}$ atom in the tube, as indicated by the calculated smallest $\mathrm{N}-\mathrm{H}$ distance (table 1). ${ }^{48}$

To evaluate noncovalent adsorption between vitamins B3 and $\mathrm{C}$ and $(5,0)$ BNNT, we used the adsorption energy $\left(E_{\mathrm{ad}}\right)$, charge transfer $(Q)$ and the equilibrium distance $(D)$ between the $(5,0)$ BNNT and vitamin (equilibrium distance is defined as the nearest distance between atoms of respective vitamin and BNNT) (see table 1).

Table 1. Calculated $E_{\mathrm{ad}}($ in $\mathrm{eV}), E_{\mathrm{g}}($ in $\mathrm{eV})$, equilibrium distance, $D(\AA)$ and transferred charge (in e) of the BNNTvitamin $\mathrm{B} 3$ and $\mathrm{BNNT}$-vitamin $\mathrm{C}$ complexes.

\begin{tabular}{lcccc}
\hline System & $E_{\mathrm{ad}}(\mathrm{eV})$ & $E_{\mathrm{g}}(\mathrm{eV})$ & $D(\AA)$ & $Q(\mathrm{e})$ \\
\hline BNNT-vitamin B3 & -0.530 & 4.013 & 1.883 & -0.020 \\
BNNT-vitamin C & -1.358 & 2.473 & 1.576 & 0.657 \\
\hline
\end{tabular}

Adsorption energies of vitamin molecules on $(5,0)$ BNNT are calculated using the basis set superposition error (BSSE). This correction is done through the counterpoise method using ghost atoms as follows:

$$
\begin{aligned}
E_{\mathrm{ad}}= & E(\mathrm{BNNT}-\text { vitamin })-\left[E\left(\mathrm{BNNT}-\text { vitamin }_{\text {ghost }}\right)\right. \\
& \left.+E\left(\text { vitamin }-\mathrm{BNNT}_{\text {ghost }}\right)\right],
\end{aligned}
$$

where $E$ (BNNT-vitamin) is the total energy of BNNTvitamin complex. Ghost subsystems correspond to the additional localized basis centred at the atomic position of the vitamin or BNNT, but without any atomic potential. By including these ghost subsystems, correct binding energy is defined as the density functional theory total energy difference between the complex system and two subsystems. ${ }^{49} E_{\text {ad }}<0$ denotes exothermic adsorption which means that the adsorption is stable energetically relative to the separated nanotube and vitamin. Results in table 1 show that absorption of vitamins $\mathrm{B} 3$ and $\mathrm{C}$ on $(5,0) \mathrm{BNNT}$ is an exothermic process with adsorption energies of $-0.530 \mathrm{eV}$ and $-1.358 \mathrm{eV}$, respectively. There is no chemical bond formation between the BNNT and vitamins B3 and C. Binding energy confirms that absorption process of vitamin $\mathrm{B} 3$ on BNNT is physisorption. In contrast, when vitamin $\mathrm{C}$ interacts with BNNT, absorption process is chemisorption. 
On the other hand, influence of vitamins B3 and C adsorption on electronic properties such as spatial distribution of molecular orbitals (MOs), density of state (DOS), molecular orbital and charge transfer are important to obtain more details about the interaction of vitamins and BNNT.

Charge transfer is one of the key factors that facilities adsorption of adsorbate on the adsorbent. We provide the $Q$ of vitamin molecules to BNNT using $\mathrm{NBO}^{50,51}$ charges, which is less sensitive to the selected basis sets than the Mullikan ${ }^{52}$ charge analysis. Noncovalent adsorption of vitamins B3 and C on the BNNT leads to an amount of charge transfer. The positive and negative values correspond to charge transfer from vitamin to $(5,0)$ BNNT and charge transfer from $(5,0)$ BNNT to vitamin, respectively. From table 1, it can be seen that charge transfer is -0.020 and 0.657 electrons for BNNT-vitamin B3 and BNNT-vitamin C complexes, respectively. Study of the adsorption energy and charge transfer of BNNT-vitamin B3 highlights that vitamin $\mathrm{B} 3$ and $\mathrm{BNNT}$ interact rather weakly, which is a result of the van der Waals attraction. Equilibrium distances $(D)$ of $(5,0)$ BNNT and vitamins $\mathrm{B} 3$ and $\mathrm{C}$ are $1.883 \AA\left(\mathrm{R}_{\mathrm{N} 40-\mathrm{H} 64}\right)$ and $1.575 \AA\left(\mathrm{R}_{\mathrm{N} 49-\mathrm{H} 12}\right)$, respectively.

Energy levels of molecular orbitals, especially HOMO and LUMO, are excellent indicators of many molecular properties. We study the difference between HOMO and LUMO, known as the HOMO-LUMO energy gap $\left(E_{\mathrm{g}}=E_{\mathrm{LUMO}}-E_{\mathrm{HOMO}}\right)$. Calculated values of $E_{\mathrm{g}}$ of BNNT-vitamin B3 and BNNT-vitamin C complexes are given in table 1. The HOMO-LUMO energy gap of pure $(5,0) \mathrm{BNNT}$ is $3.933 \mathrm{eV}$. Upon adsorption of vitamins B3 and C on tube, $E_{\mathrm{g}}$ of BNNT-vitamin B3 and BNNT-vitamin $\mathrm{C}$ complexes change to 4.013 and $2.473 \mathrm{eV}$, respectively. These results show that vitamin B3 absorption can little change electrical conductivity and transport properties of BNNT. Therefore, it can be concluded that BNNT cannot be an appropriate sensor for vitamin B3.

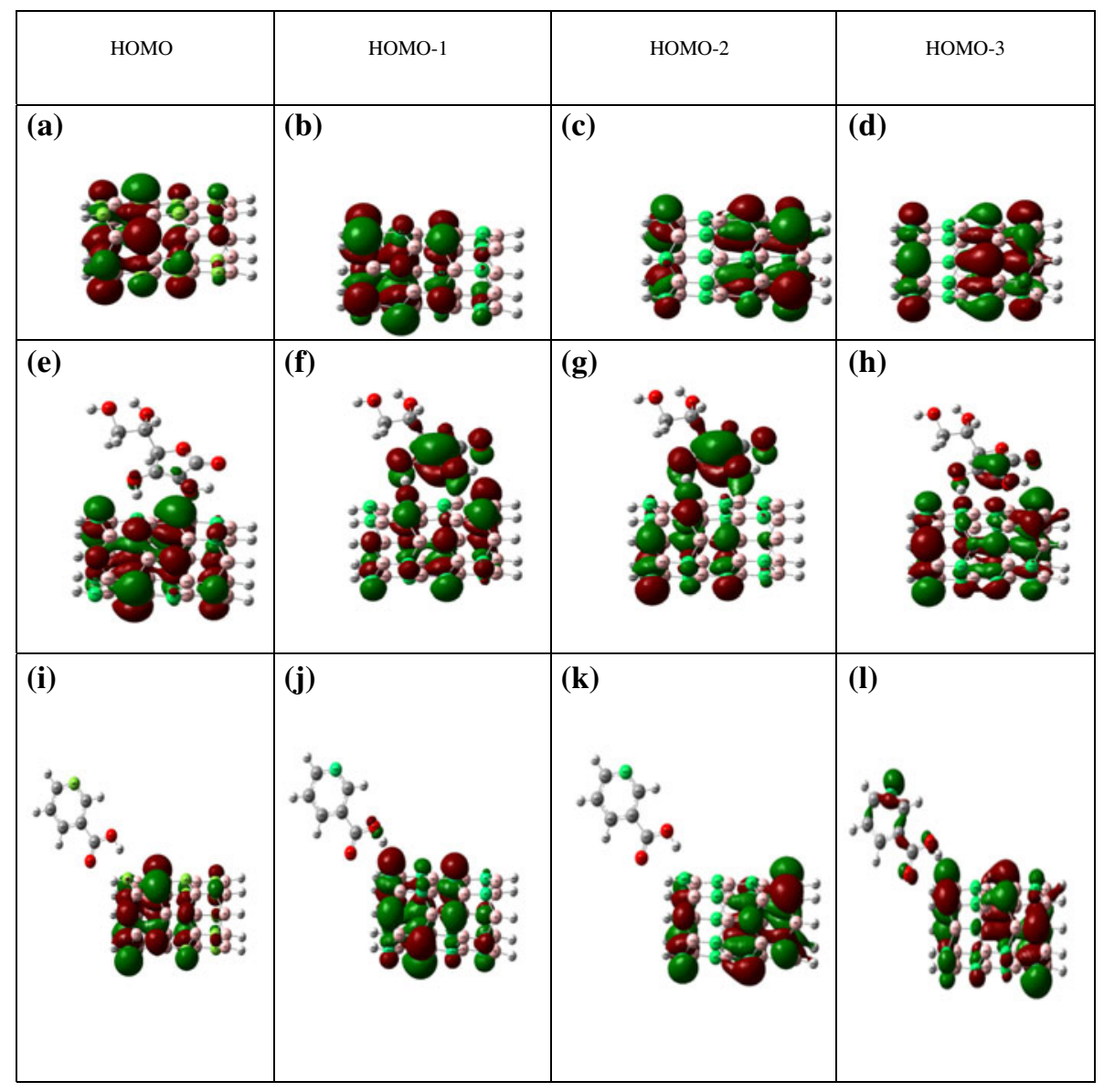

Figure 2. Orbital spatial distribution of HOMO, HOMO-1, HOMO-2 and HOMO-3 $(\mathbf{a}, \mathbf{b}, \mathbf{c}, \mathbf{d})$ optimized structure of $(5,0)$ BNNT $(\mathbf{e}, \mathbf{f}, \mathbf{g}, \mathbf{h})$ BNNT-vitamin C complex and (i, j, k, l) BNNT-vitamin B3 complex, respectively. 
One of the important applications of noncovalent and covalent adsorption on BNNTs is to modify the electronic structures and thus widen their potential applications. The change in electro-conductivity of the BNNT systems is an important process in the sensor industry. It is well-known that $E_{\mathrm{g}}$ is a major factor determining the electrical conductivity of a material and there is a classic relation between them as follows: ${ }^{53}$

$$
\sigma \propto \exp \left(-E_{\mathrm{g}} / 2 k T\right)
$$

where $\sigma$ is the electrical conductivity, $T$ is the temperature and $k$ is the Boltzmann constant. According to the equation, larger $E_{\mathrm{g}}$, at a given temperature, leads to smaller electrical conductivity. Therefore, the observed decrement in $E_{\mathrm{g}}$ of the BNNT upon the adsorption process leads to change in electrical conductivity of BNNT. In BNNT-vitamin C, $E_{\mathrm{g}}$ decreases from 3.933 for pristine BNNT to $2.473 \mathrm{eV}$ upon adsorption of vitamin C. Considerable change in $E_{\mathrm{g}}$ value demonstrates high sensitivity of electronic properties of BNNT towards presence of vitamin C. Therefore, presence of vitamin C may be detected by calculating conductivity change of BNNT before and after the adsorption process. Results suggest that BNNT may be a promising candidate for serving as effective sensors to detect vitamin C.

It is worth mentioning that very strong interactions are not favourable in sensors because it implies that desorption of the adsorbate could be difficult and the device may suffer from long recovery times. If $E_{\mathrm{ad}}$ is significantly increased, much longer recovery time is expected based on the conventional transition state theory:

$$
\tau=\exp v_{0}^{-1}\left(-E_{\mathrm{ad}} / k T\right)
$$

where $T$ is the temperature, $k$ is the Boltzmann constant, and $v_{0}$ is the attempt frequency. According to this equation, more negative $E_{\text {ad }}$ values will prolong recovery time in an exponential manner. Adsorption energy of vitamin $\mathrm{C}$ on BNNT is not too large to hinder recovery of BNNT and therefore the sensor will possess short recovery times. ${ }^{54}$

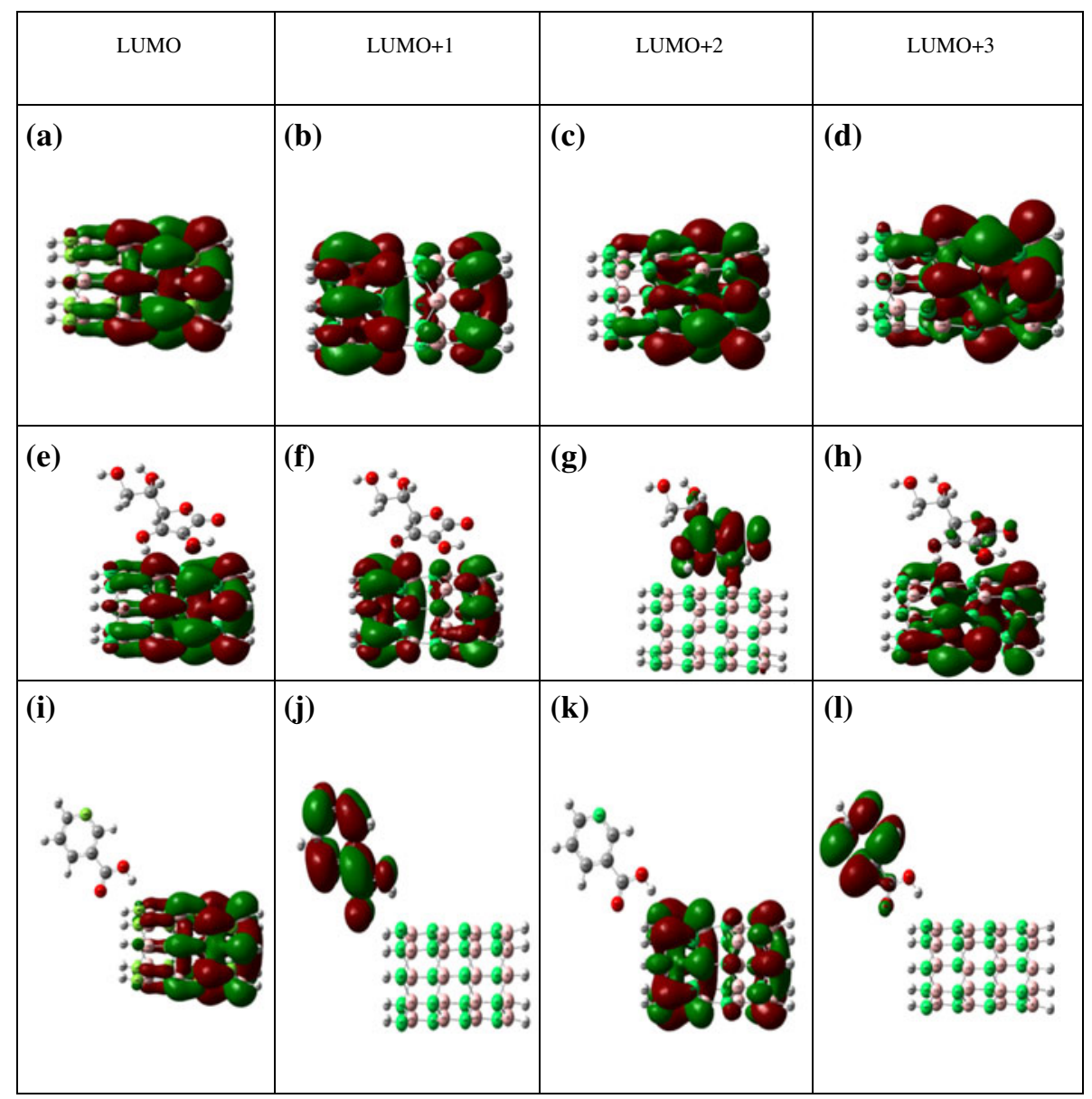

Figure 3. Orbital spatial distribution of LUMO, LUMO+1, LUMO+2 and LUMO+3 (a, b, c, d), optimized structure of $(5,0)$ BNNT $(\mathbf{e}, \mathbf{f}, \mathbf{g}, \mathbf{h})$, BNNT-vitamin C complex $(\mathbf{i}, \mathbf{j}, \mathbf{k}, \mathbf{l})$ and BNNT-vitamin B3 complex, respectively. 
To further explain the electrical properties of BNNTvitamin $\mathrm{C}$ and $\mathrm{BNNT}-$ vitamin $\mathrm{B} 3$ complexes and to examine the sensitivity of BNNT to vitamins, we studied spatial distribution of molecular orbitals including HOMO, HOMO-1, HOMO-2, HOMO-3 and LUMO, LUMO+1, LUMO+2, LUMO+3 and DOS. Spatial distribution was performed to obtain a better understanding of the interaction of vitamins $\mathrm{C}$ and $\mathrm{B} 3$ with $(5,0)$ BNNT. Figures 2 and 3 illustrate spatial distribution of HOMO, HOMO-1, HOMO-2, HOMO3 and LUMO, LUMO $+1, \mathrm{LUMO}+2, \mathrm{LUMO}+3$ of the $(5,0)$ BNNT and BNNT-vitamin C and BNNTvitamin $\mathrm{B} 3$ complexes. As shown in figure 2, HOMO and HOMO-1 of the $(5,0)$ zigzag BNNT model are located on the nitrogen atoms and mainly at the end of $\mathrm{N}$-terminated and HOMO-2, and HOMO-3 is mainly distributed on the nitrogen atoms at the two ends of the tube and corresponds to the lone pair of electron on nitrogen atoms. In contrast, the LUMO, LUMO+2 and LUMO +3 are uniformly distributed throughout the $\mathrm{B}-\mathrm{N}$ bonds and mainly at the ends of B-terminated and $\mathrm{LUMO}+1$ is localized throughout the $\mathrm{B}-\mathrm{N}$ bonds mostly at the two ends of the tube. The greatest extension values of LUMO suggest the high reactivity of the $\mathrm{B}-\mathrm{N}$ pairs at the end of B-terminated towards nucleophilic attack. The small contribution of LUMO at $\mathrm{N}$-terminated signifies less reactivity of these atoms towards nucleophilic attack. Figure $1 \mathrm{~b}$ shows the highest contributions of electron density on nitrogen atoms and mainly at the end of N-terminated on the HOMO. This observation reveals that $\mathrm{N}$-terminated is a highly favourable site for electrophilic attack.

For the $(5,0)$ BNNT-vitamin C, HOMO and HOMO3 are mainly gathered on the nitrogen atoms of the

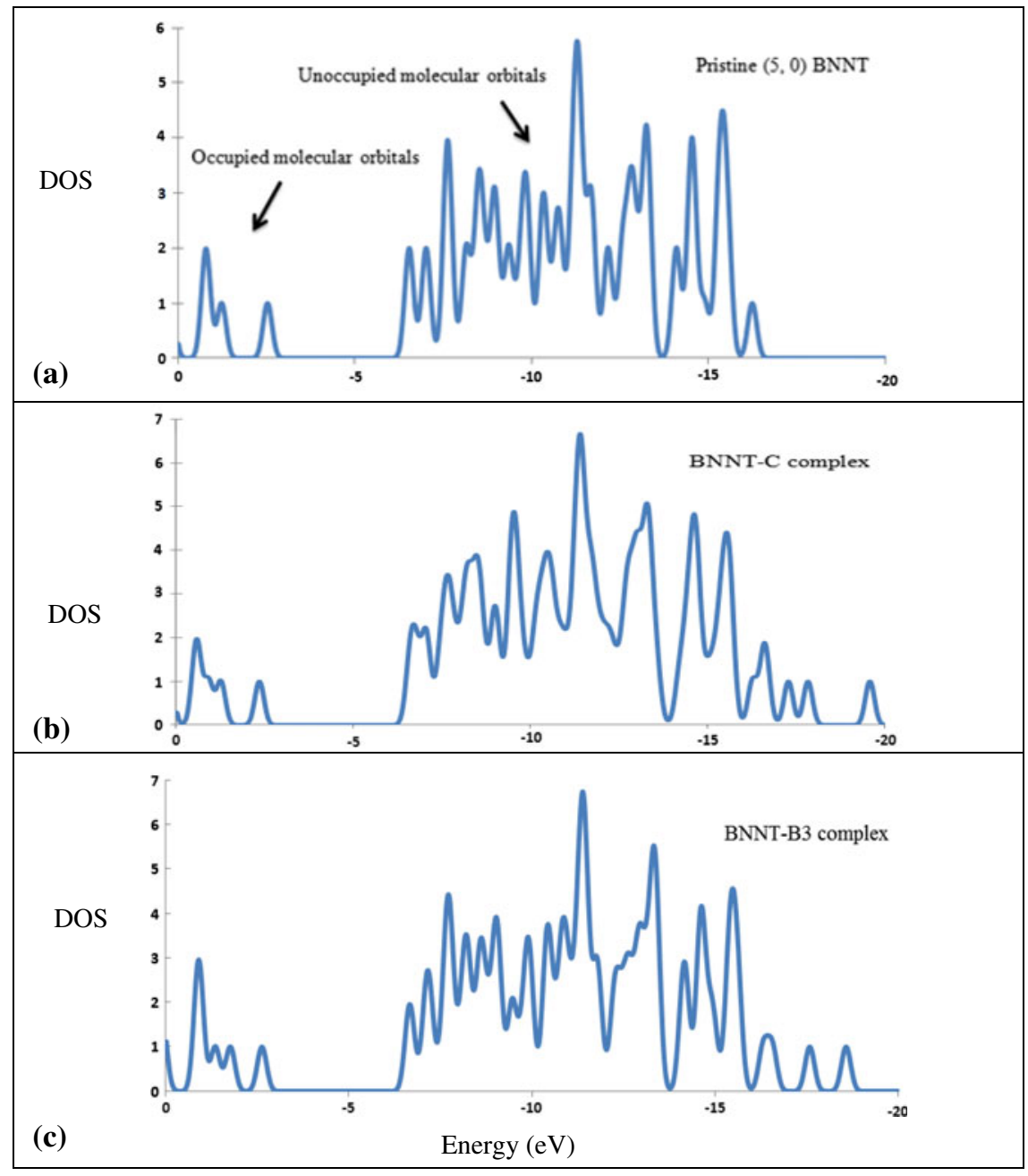

Figure 4. Density of states (DOS) of (a) pristine $(5,0)$ BNNT and noncovalent adsorption of (b) BNNT-vitamin C complex and (c) BNNT-vitamin B3 complex. 
Table 2. Calculated $E_{\text {ad }}($ in $\mathrm{eV}), E_{g}(\mathrm{in} \mathrm{eV})$, equilibrium distance, $D(\AA)$ and transferred charge (in e) of BNNT-radical vitamin $\mathrm{B} 3$ and $\mathrm{BNNT}$-radical vitamin $\mathrm{C}$ on $\mathrm{B}$ and $\mathrm{N}$ sites.

\begin{tabular}{lcccr}
\hline System & $E_{\mathrm{ad}}(\mathrm{eV})$ & $E_{\mathrm{g}}(\mathrm{eV})$ & $D(\AA)$ & $Q(\mathrm{e})$ \\
\hline BNNT-radical vitamin B3 (B and N sites) & -1.010 & 3.628 & 1.515 & -0.320 \\
BNNT-radical vitamin C (B site) & -2.664 & 2.275 & 1.473 & -0.223 \\
BNNT-radical vitamin C (N site) & -1.063 & 2.024 & 1.456 & -0.260 \\
\hline
\end{tabular}

nanotube and HOMO-1, HOMO-2 are localized on the vitamin $\mathrm{C}$ ring and tube, while LUMO, $\mathrm{LUMO}+1$ and LUMO +3 are distributed on the edge $\mathrm{B}-\mathrm{N}$ bonds of the nanotube, which are basically due to unequal charge distribution along the edge $\mathrm{B}-\mathrm{N}$ bonds and $\mathrm{LUMO}+2$ are localized on the vitamin $\mathrm{C}$ ring.
Also figures 2 and 3 show that HOMO, HOMO1, HOMO-2, HOMO-3 for the $(5,0)$ BNNT-vitamin B3 complexes are localized on the more electronegative nitrogen atoms, and LUMO and LUMO+2 of the BNNT-vitamin B3 complexes are distributed on the edge $\mathrm{B}-\mathrm{N}$ bonds of the nanotube and LUMO+1

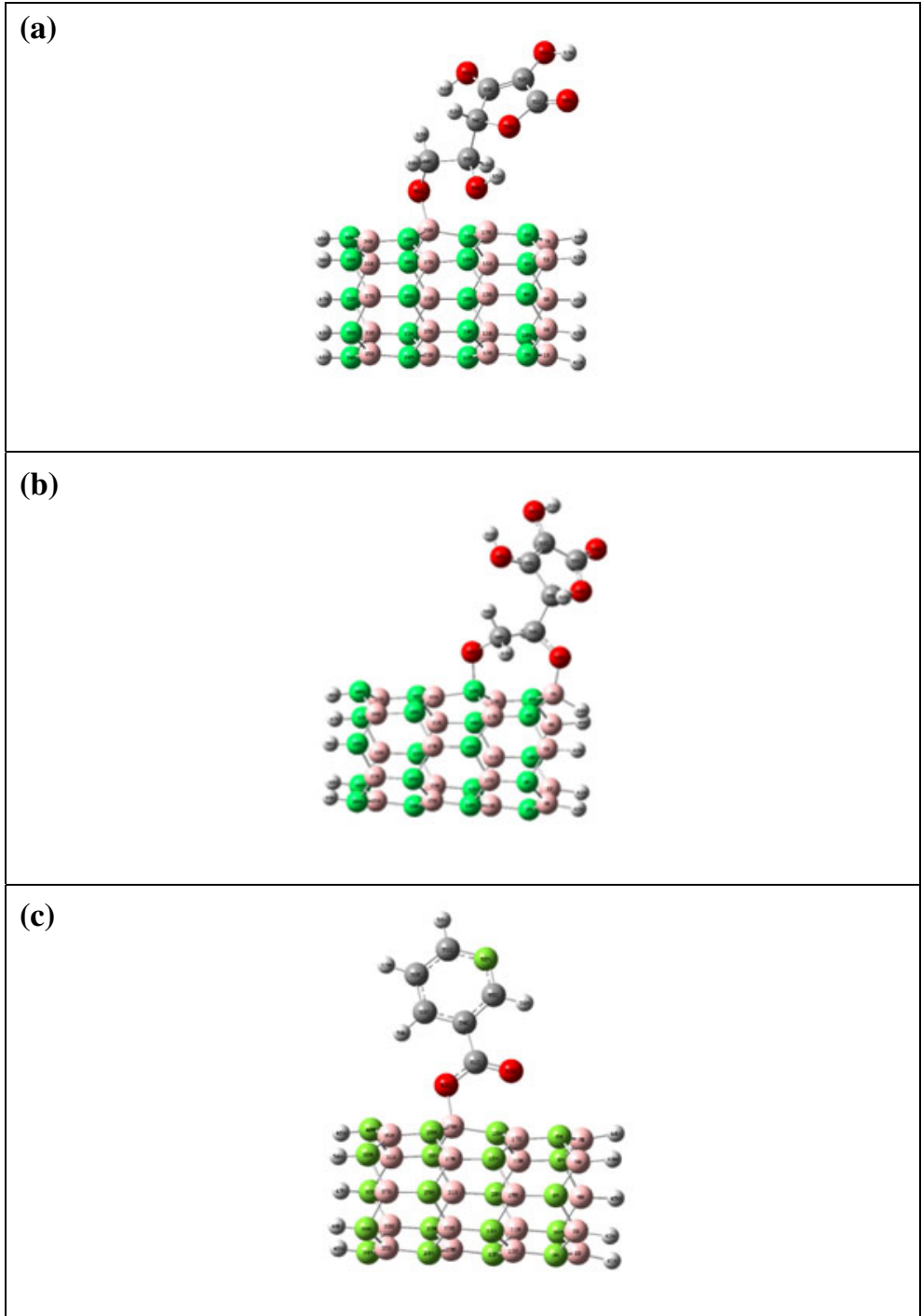

Figure 5. Fully optimized structures of (a) BNNT-radical vitamin C on B site, (b) BNNT-radical vitamin $\mathrm{C}$ on $\mathrm{N}$ site, (c) BNNT-radical vitamin $\mathrm{B} 3$ on $\mathrm{B}$ and $\mathrm{N}$ sites. 
and $\mathrm{LUMO}+3$ are localized on the vitamin $\mathrm{B} 3$ ring.

We calculated DOS of BNNT-vitamin C and BNNTvitamin B3 complexes and compared with the pristine $(5,0)$ BNNT in figure 4 . The DOS of the $(5,0)$ BNNT shows the significant changes due to vitamin $\mathrm{C}$ adsorption. The DOS plot of the BNNT-vitamin B3 shows that vitamin B3 noncovalent adsorption has no sensible effect on the electronic properties of BNNT; thus, in the noncovalent interaction of BNNT with vitamin B3, BNNT retains its original properties. On the other hand, from the energy point of view, vitamin B3 easily separate from the BNNT surface. Thus, we believe that the present result will provide useful guidance to develop novel BNNT-based drug delivery for vitamin B3.

\subsection{Covalent interaction of vitamins $B 3$ and $C$ with $(5,0)$ BNNT}

In this section, we report the interaction of vitamin B3 and $\mathrm{C}$ radicals with pristine $(5,0)$ BNNT. For covalent adsorption of vitamins B3 and C, one hydrogen atom was removed from hydroxyl group, and the remaining oxygen atom was brought closer to the $\mathrm{B}$ atom ( $\mathrm{B}$ site) and $\mathrm{N}$ atom ( $\mathrm{N}$ site) in the middle of the BNNT surface. Corresponding configurations were labelled BNNT-radical vitamin C and BNNT-radical vitamin B3. Optimized conformers are visualized in figure 5. Optimization geometries show that in the radical vitamin $\mathrm{B} 3$ at $\mathrm{N}$ site, a configuration similar to $\mathrm{B}$ site is formed. Also covalent interaction of radical vita$\min \mathrm{C}$ on $\mathrm{N}$ site leads to formation of a single covalent $\mathrm{B}_{7 \mathrm{BNNT}}-\mathrm{O}_{64}$ bond.

Adsorption energies, charge transfer, band gap and equilibrium distance are presented in table 2. Equilibrium distance and calculated adsorption energies are found to be $1.515 \AA$ and $-1.010 \mathrm{eV}$ for BNNT-radical vitamin $\mathrm{B} 3$ at $\mathrm{B}$ and $\mathrm{N}$ sites, $1.473 \AA$ and $-2.664 \mathrm{eV}$ for BNNT-radical vitamin $\mathrm{C}$ at $\mathrm{B}$ site and $1.456 \AA$ and $-1.063 \mathrm{eV}$ for BNNT-radical vitamin $\mathrm{C}$ at $\mathrm{N}$ site. Based on the calculated medium $E_{\text {ad }}$ values, which indicate interaction between the tube and vitamins B3 and $\mathrm{C}$ radical is in a suitable extent (neither too weak to capture the molecule or too strong to be de-adsorbed), we consider BNNT could be used as potential adsorbents of vitamins B3 and $\mathrm{C}$ radical. Table 2 shows

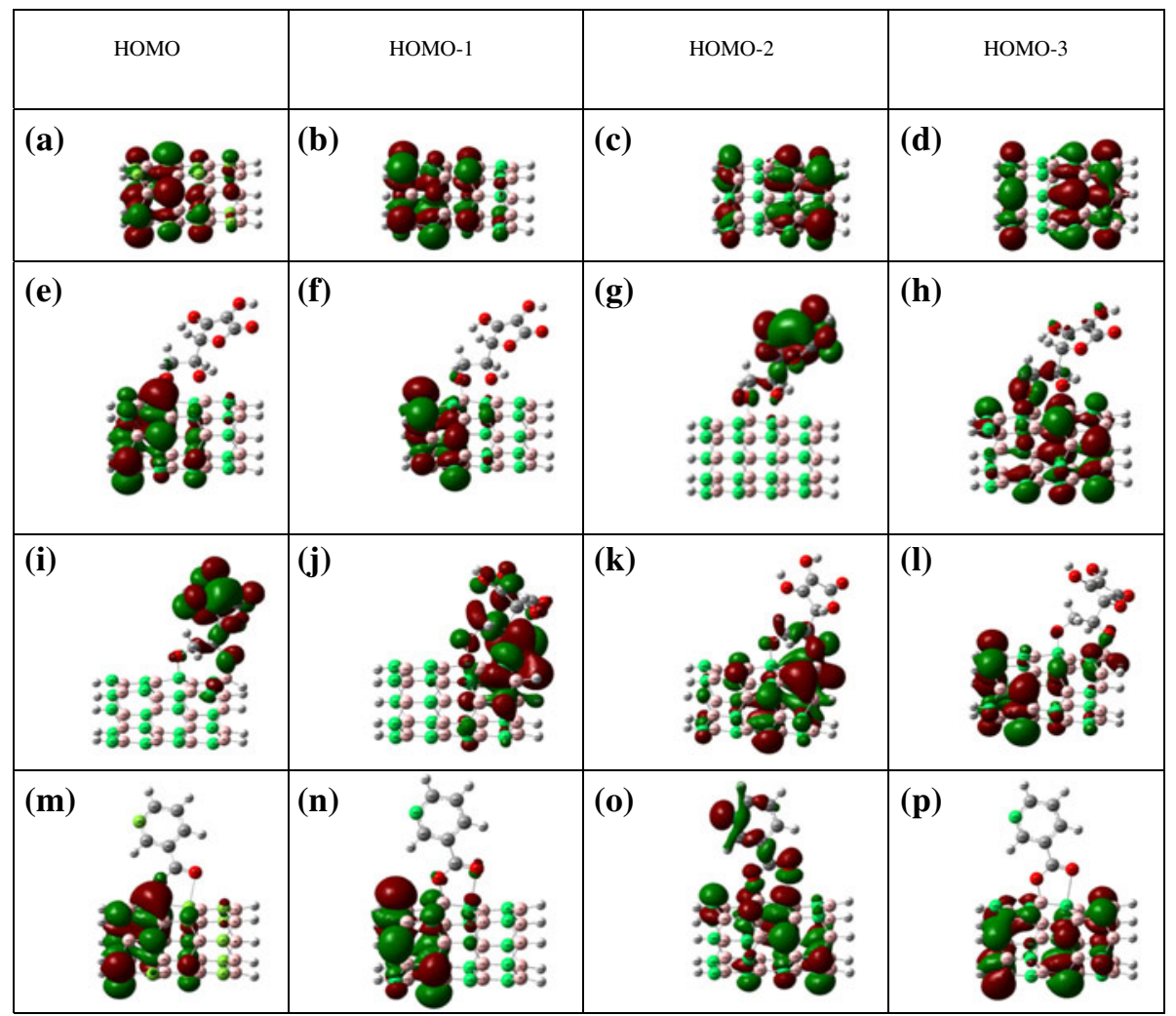

Figure 6. Orbital spatial distribution of HOMO, HOMO-1, HOMO-2 and HOMO-3 $(\mathbf{a}, \mathbf{b}, \mathbf{c}, \mathbf{d})$, optimized structure of $(5,0)$ BNNT $(\mathbf{e}, \mathbf{f}, \mathbf{g}, \mathbf{h})$, BNNT-radical vitamin C on $\mathrm{B}$ site $(\mathbf{i}, \mathbf{j}, \mathbf{k}, \mathbf{l})$ and $\mathrm{BNNT}$-radical vitamin $\mathrm{C}$ on $\mathrm{N}$ site $(\mathbf{m}, \mathbf{n}, \mathbf{o}, \mathbf{p})$ and BNNT-radical vitamin $\mathrm{B} 3$ on $\mathrm{B}$ and $\mathrm{N}$ sites, respectively. 
that transferred charge for all the systems is significant. Negative values of transferred charge for BNNTradical vitamin B3 and BNNT-radical vitamin $\mathrm{C}$ at $\mathrm{B}$ and $\mathrm{N}$ sites correspond to the charge transfer from $(5,0)$ BNNT to vitamin.

In BNNT-radical vitamin B3, $E_{\mathrm{g}}$ decreases from 3.933 for pristine BNNT to $3.628 \mathrm{eV}$ upon the adsorption of radical vitamin $\mathrm{B} 3$, indicating that the effect of adsorption process of vitamin $\mathrm{B} 3$ radical on BNNT conductance is negligible. This suitable interaction provides a potential way to functionalize BNNT without changing its electronic structure by vitamin B3 radical. Calculated $E_{\mathrm{g}}$ values of BNNT-radical vitamin C at B and $\mathrm{N}$ sites are 2.275 and $2.024 \mathrm{eV}$, respectively. Therefore, in comparison with the pristine BNNT (3.933 eV), adsorption of radical vitamin $\mathrm{C}$ at $\mathrm{B}$ and $\mathrm{N}$ sites on BNNT decreases energy gap of the tube, and increases their electrical conductance.

To get better insight into covalent interactions of BNNT with vitamin radicals, figures 6 and 7 show spatial distribution of molecular orbitals including
HOMO, HOMO-1, HOMO-2, HOMO-3 and LUMO, $\mathrm{LUMO}+1, \mathrm{LUMO}+2, \mathrm{LUMO}+3$. In the BNNTradical vitamin $\mathrm{C}$ at $\mathrm{B}$ site (figure 6), $\mathrm{HOMO}$ and HOMO-1 are gathered on the nitrogen atoms of the nanotube and mainly at the end of N-terminated, HOMO-2 is mainly localized on the radical vitamin $\mathrm{C}$ and HOMO-3 is mainly gathered on the BNNT and vitamin. It can be seen from figure 7 that charge of LUMO is mostly distributed at the B-terminated of BNNT and LUMO+1 is gathered on the radical vitamin $\mathrm{C}, \mathrm{LUMO}+2$ and LUMO +3 are distributed mostly on the $\mathrm{B}-\mathrm{N}$ bonds of the nanotube.

Also, it can be seen in figures 6 and 7 that in BNNTradical vitamin $\mathrm{C}$ at $\mathrm{N}$ site, $\mathrm{HOMO}$ is localized over the radical vitamin $\mathrm{C}, \mathrm{HOMO}-1$ is gathered over the nanotube and radical vitamin $\mathrm{C}$; whereas HOMO-2 and HOMO-3 are distributed on the $(5,0)$ BNNT. The LUMO and LUMO +1 of the BNNT-radical vitamin C at $\mathrm{N}$ site are localized over the nanotube and the radical vitamin $\mathrm{C}$ and $\mathrm{LUMO}+2$ and $\mathrm{LUMO}+3$ are localized over the $(5,0)$ BNNT.

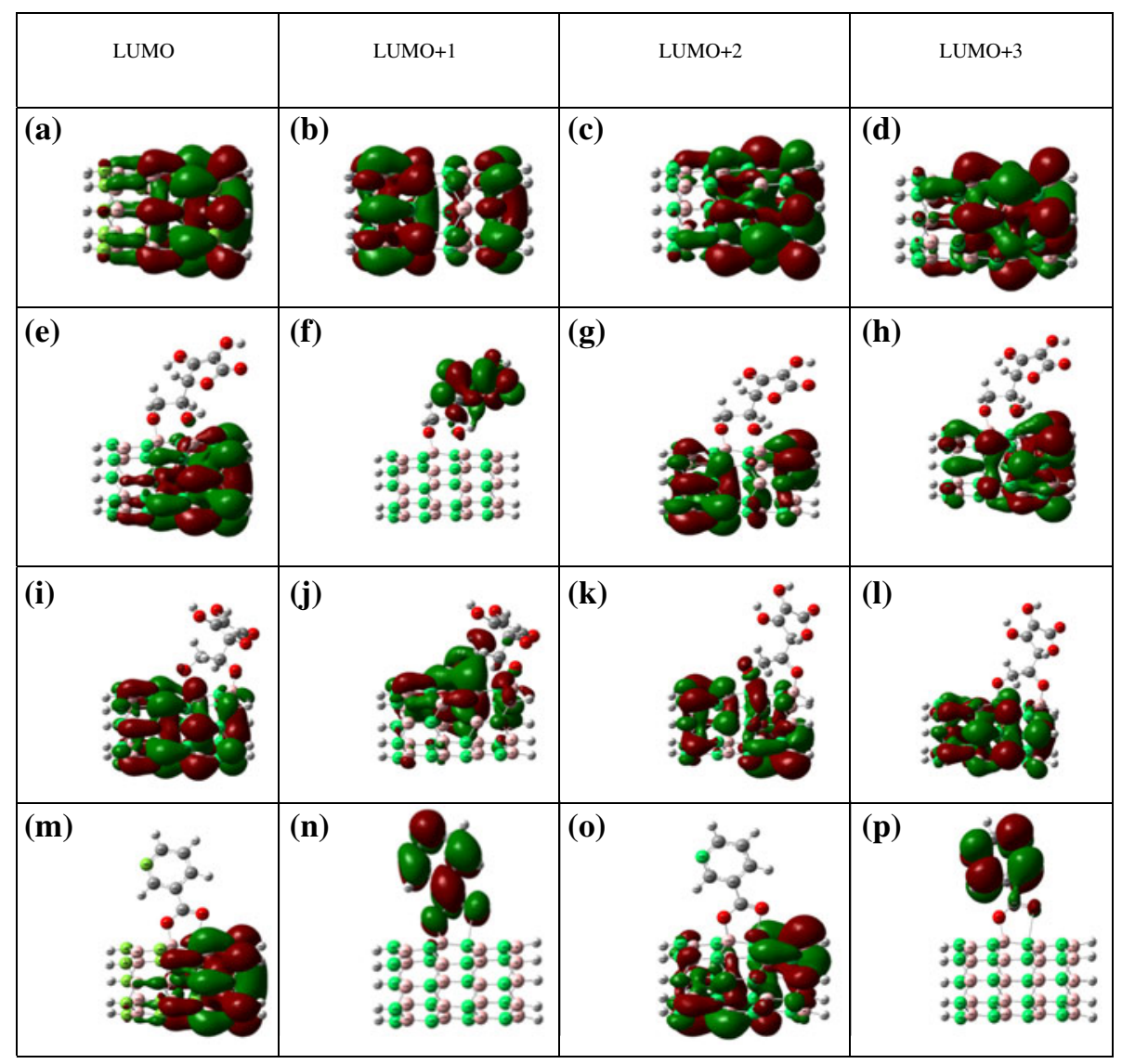

Figure 7. Orbital spatial distribution of LUMO, LUMO+1, LUMO+2 and LUMO+3 (a, b, c, d), optimized structure of $(5,0)$ BNNT $(\mathbf{e}, \mathbf{f}, \mathbf{g}, \mathbf{h})$, BNNTradical vitamin $\mathrm{C}$ on $\mathrm{B}$ site $(\mathbf{i}, \mathbf{j}, \mathbf{k}, \mathbf{l})$ and $\mathrm{BNNT}$-radical vitamin $\mathrm{C}$ on $\mathrm{N}$ site $(\mathbf{m}, \mathbf{n}$, $\mathbf{o}, \mathbf{p})$ and BNNT-radical vitamin B3 on B and N sites, respectively. 


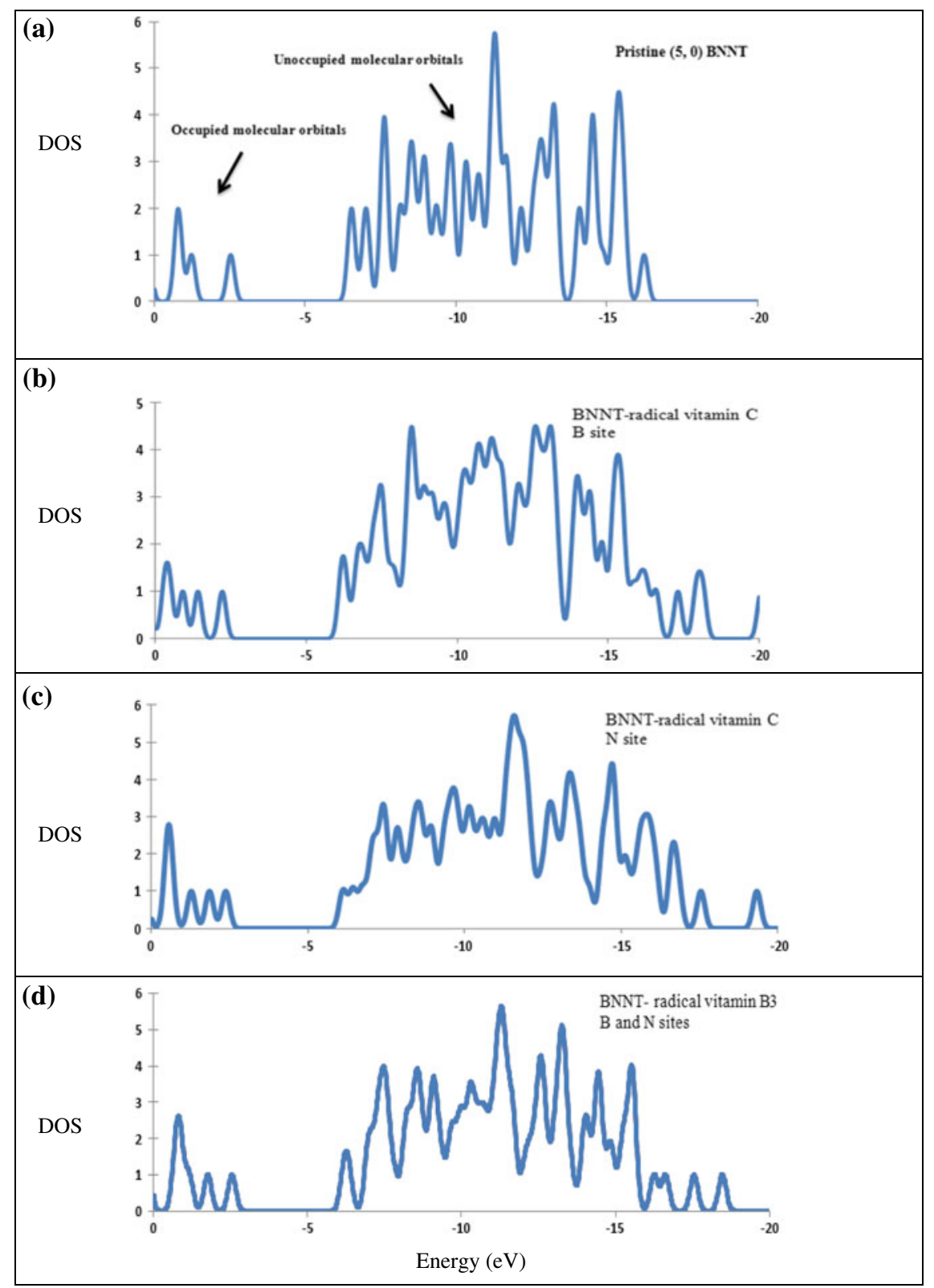

Figure 8. Density of states (DOS) of (a) pristine $(5,0)$ BNNT, (b) BNNT-radical vitamin $\mathrm{C}$ on $\mathrm{B}$ site, (c) BNNT-radical vitamin $\mathrm{C}$ on N site and (d) BNNT-radical vitamin $\mathrm{B} 3$ on $\mathrm{B}$ and $\mathrm{N}$ sites.

In BNNT-radical vitamin B3, HOMOs spread over the $(5,0)$ BNNT and LUMO and LUMO +2 are mostly localized on the nanotube, whereas LUMO+1 and LUMO +3 are distributed over the radical vitamin B3.

DOSs of pristine $(5,0)$ BNNT with adsorbed vitamins $\mathrm{B} 3$ and $\mathrm{C}$ radical are shown in figure 8. Compared with DOSs of the isolated BNNT, BNNT-radical vitamin $\mathrm{C}$ at $\mathrm{B}$ and $\mathrm{N}$ sites show remarkable changes due to vitamin $\mathrm{C}$ radical adsorption. This fact indicates that the $(5,0)$ BNNT presents a considerable change in the electronic and transport properties upon absorption of vitamin $\mathrm{C}$ radical at $\mathrm{B}$ and $\mathrm{N}$ sites. This result reveals a promising alternative for the use of BNNT as a sensing device to detect the vitamin $\mathrm{C}$ radical. It can be found in figure 8 that the DOS of BNNT-radical vitamin B3, is not affected by the radical vitamin B3 adsorption.

\section{Conclusion}

By performing density functional theory calculations, we have studied the noncovalent and covalent adsorptions of vitamins B3 and C on $(5,0)$ BNNT. We find 
that the electronic properties of BNNT by the noncovalent and covalent interactions with vitamin B3 are little changed. These adsorptions are interesting because the vitamin can be easily removed from the BNNT surface, keeping original properties of the BNNT intact, which is one of the important factors for drug delivery. Hence, based on these theoretical results, BNNT can be used as material for delivery of vitamin B3.

Also, our calculations show that adsorption of vitamin $\mathrm{C}$ and vitamin $\mathrm{C}$ radical on BNNT is favourable from the energy point of view. We consider BNNT could be used as potential adsorbent of vitamins B3 radical. Electronic structures of BNNT present remarkable changes in the adsorption of vitamin $\mathrm{C}$ and its radical. Based on this theoretical result, we propose that BNNT can be used as a potential resource for vitamin $\mathrm{C}$ and vitamin $\mathrm{C}$ radical sensors. However, this study might be helpful in widening the application of BNNT in biosensors and drug delivery.

\section{Acknowledgements}

Authors thank the Iranian Nanotechnology Initiative Council and University of Mazandaran for research facilities and financial grants.

\section{References}

1. Ciofani G, Raffa V, Yu J, Chen Y, Obata Y, Takeoka S, Menciassi A and Cuschieri A 2009 Curr. Nanosci. 533

2. Arsawang U, Saengsawang $\mathrm{O}$ and Rungrotmongkol $\mathrm{T}$ 2011 J. Mol. Graphics Model. 29591

3. Yinghuai Z, Peng A T, Carpenter K, Maguire J A, Hosmane N S and Takagaki M 2005 J. Am. Chem. Soc. 1279875

4. Balasubramanian K and Burghard M 2006 Anal. Bioanal. Chem. 385452

5. Couvreur P and Vauthier C 2006 Pharm. Res. 231417

6. Prato M, Kostarelos K and Bianco A 2008 Acc. Chem. Res. 4160

7. Kam N W S and Dai H 2006 Phys. Status Solidi 243 3561

8. Klumpp C, Kostarelos K, Prato M and Bianco A 2006 Biochim. Biophys. Acta $\mathbf{1 7 5 8} 404$

9. Moscatello J P, Wang J, Ulmen B, Kayastha V K, Xie M, Mensah S L, Wu S, Pandey A, Lee C H, Prasad A and Yap Y K 2007 ECST 31

10. Zhong X, Mukhopadhyay S, Gowtham S, Pandey R and Karna S P 2013 Appl. Phys. Lett. 102133705

11. Fam D W H, Palaniappan A, Tok A I Y, Liedberg B and Moochhala S M 2011 Sensors Actuat. B: Chem. 1571

12. Xie Y, Huo Y P and Zhang J M 2012 Appl. Surf. Sci. 258 6391

13. Chowdhury $\mathrm{R}$ and Adhikari S 2011 IEEE Trans. Nanotechnol. 10659
14. Balasubramanian $\mathrm{K}$ and Burghard M 2006 Anal. Bioanal. Chem. 385452

15. Terrones M, Romo-Herrera J M, Cruz-Silva E, Muñozsandoval F, Velázquzar J J, Terrones H, Bando Y and Golberg D 2007 Mater. Today 1030

16. Li Y, Zhou Z and Zhao J 2007 J. Phys. Chem. 127 184705

17. Gou G Y, Pan B C and Shi L 2010 Acs Nano 41313

18. He W, Li Z, Yang J and Hou J G 2008 J. Chem. Phys. 4 129024710

19. Chen X, Wu P, Rousseas M, Okawa D, Gartner Z, Zettl A and Bertozzi C R 2009 J. Am. Chem. Soc. 131890

20. Ciofani G, Raffa V, Menciassi A and Cuschieri A 2009 Nano Today 48

21. Ciofani G, Raffa V, Yu J, Chen Y, Obata Y, Takeoka S, Menciassi A and Cuschieri A 2009 Curr. Nanosci. 533

22. Zhi C, Bando Y, Tang C and Golberg D 2005 J. Am. Chem. Soc 12717144

23. Ciofani G, Raffa V, Menciassi A and Dario P $2008 \mathrm{~J}$. Nanosci. Nanotechnol. 86223

24. Ciofani G, Raffa V, Menciassi A and Cuschieri A 2008 Biotechnol. Bioeng. 101850

25. Yang CK 2011 Comput. Phys. Commun. 18239

26. Mukhopadhyay S, Gowtham S, Scheicher R H, Pandey R and Karna S P 2010 Nanotechnology 21165703

27. Moradi AV, Ahmadi A, Hashemian S and Baei M T 2012 Bull. Korean Chem. Soc. 333285

28. Yua J, Chen Y and Cheng B M 2009 Solid State Commun. 149763

29. Ahmadi A, Beheshtian J and Hadipour N L 2008 Struct. Chem. 22183

30. Li Y F, Zhou Z and Zhao J J 2006 J. Am. Chem. Soc. 128 12001

31. Zhang Z and Guo W 2009 J. Am. Chem. Soc. 1316874

32. Li Y, Zhou Z and Zhao J 2008 Nanotechnology 19 015202

33. He W, Li Z, Yang J and Hou J G 2008 J. Chem. Phys. 128(16) 164701

34. Mukhopadhyay S, Gowtham S, Scheicher R H, Pandey R and Karna S P 2010 Nanotechnology 21165703

35. Velayudham S, Lee C H, Xie M, Blair D, Bauman N, Yap Y K, Green S A and Liu H 2010 Appl. Mater. Interfaces 2104

36. Zhao J X and Ding Y H 2009 Chem. Phys. 11621

37. Zhao J X and Ding Y H 2008 J. Phys. Chem. C. 112 20206

38. Krishnan S, Vadapoo R, Riley K E and Velev J P 2011 Phys. Rev. B84 165408

39. Castillo J J, Rozo C E, Castillo-León J, Rindzevicius T, Svendsen W E, Rozlosnik N, Boisen A and Martínez F 2013 Chem. Phys. Lett. 56460

40. Frisch M J, Trucks G W, Schlegel H B, Scuseria G E, Robb M A, Cheeseman J R, Montgomery J A, Vreven T, Kudin K N, Burant J C, Millam J M, Iyengar S S, Tomasi J, Barone V, Mennucci B, Cossi M, Scalmani G, Rega N, Petersson G A, Nakatsuji H, Hada M, Ehara M, Toyota K, Fukuda R, Hasegawa J, Ishida M, Nakajima T, Honda Y, Kitao O, Nakai H, Klene M, Li X, Knox J E, Hratchian H P, Cross J B, Adamo C, Jaramillo J, Gomperts R, Stratmann R E, Yazyev O, Austin A J, Cammi R, Pomelli C, Ochterski J W, Ayala P Y, Morokuma K, Voth G A, Salvador P, Dannenberg J J, 
Zakrzewski V G, Dapprich S, Daniels A D, Strain M C, Farkas O, Malick D K, Rabuck A D, Raghavachari K, Foresman J B, Ortiz J V, Cui Q, Baboul A G, Clifford S, Cioslowski J, Stefanov B B, Liu G, Liashenko A, Piskorz P, Komaromi I, Martin R L, Fox D J, Keith T, Al-Laham M A, Peng C Y, Nanayakkara A, Challacombe M, Gill P M W, Johnson B, Chen W, Wong M W, Gonzalez C and Pople J A 2003 Gaussian 03; Gaussian, Inc., Pittsburgh PA

41. Chen L, Xu C and Zhang X F 2008 J. Mol. Struct. 86355

42. Chelmecka E, Pasterny K, Kupka T and Stobinski L 2012 J. Mol. Model. 182241

43. Tomiæ S, Montanari B and Harrison N M 2008 Physica E 402125

44. Zahedi E 2012 Physica B 4073841

45. Kar T, Akdim B, Duan X and Pachter R 2006 Chem. Phys. Lett. 423126
46. Saha S, Dinadayalane T C, Leszczynska D and Leszczynski J 2013 Chem. Phys. Lett. 56569

47. Mirzaei M, Meskinfam M and Yousefi M 2012 Comp. Theor. Chem. 98147

48. Song K, Zhang D and Liu C 2011 Comp. Theor. Chem. 97898

49. Menezes M V, Fagan S B, Zanella I and Mota R 2009 Microelec. J. 40877

50. Glendening E D, Reed A E, Carpenter J E and Weinhold $F$, NBO Version 3.1

51. Visit the NBO website at http://www.chem.wisc. educ/ nbo5/

52. Mulliken R S 1955 J. Chem. Phys. 231833

53. Li S 2006 Semiconductor physical electronics (Berlin: Springer)

54. Beheshtian J, Ahmadi A and Bagheri Z 2012 Sensors Actuat. B. Chem. 171846 